\title{
A new agent for the control of spasticity
}

\author{
RICHARD F. JONES, DAVID BURKE, J. E. MAROSSZEKY, AND \\ J. D. GILLIES
}

From the Department of Rehabilitation Medicine and the Division of Neurology, The Prince Henry Hospital, Sydney, and the School of Medicine, University of New South Wales, Australia

SUMMARY In a preliminary controlled trial, CIBA 34,647-Ba, a gamma aminobutyric acid derivative, was found to be more effective than placebo in reducing spasticity due to spinal injuries. In an uncontrolled trial, 34,647-Ba also appeared more effective than diazepam. The intensity of spasticity was measured electromyographically by the amplitude of the stretch reflex at various velocities, and the results were correlated with those obtained by clinical assessment. 34,647-Ba was effective in both complete and incomplete spinal cord lesions and it is suggested that it has an action at the spinal level. No significant side-effects were encountered.

There is no pharmacological agent in current use which will reliably suppress spasticity while preserving residual muscle power. Diazepam is probably the most useful but it is not always effective, and higher dosage may be precluded by the development of drowsiness.

Agents chemically related to gamma aminobutyric acid have attracted interest as possible spasmolytic drugs because of the central inhibitory effect of the parent substance. A new derivative, CIBA 34,647-Ba $(\beta$-(4-chlorophenyl) $\gamma$-aminobutyric acid) has given promising results in clinical trials in the treatment of spasticity.

Preclinical studies in CIBA Laboratories have shown that this drug depresses monosynaptic and polysynaptic reflex transmission in both spinal and decerebrate preparations. Intravenous administration in the decerebrate animal decreases the firing rate of tonically active fusimotor fibres but has no effect on the discharge rate of de-efferented muscle spindles or on the neuromuscular junction.

Most of the trials of 34,647-Ba have been based on a subjective assessment of clinical response (Bergamini, Riccio, and Bergamasco, 1966; Castaneda, 1967; Morales, 1967; Jerusalem, 1968), but in one trial electromyography was used to support the clinical assessment (Birkmayer, Danielczyk, and Weiler, 1967).

Several methods have been described for assessing spasticity objectively. They have been based on measurement of the integrated electromyogram (EMG) during passive movement or induced spasm (Levine, Jossmann, De Angelis, and Kane, 1964; Leavitt and Beasley, 1964; Levine, Jossmann,
Friend, De Angelis, and Kane, 1969) and measurement of the resistance to passive movement of the spastic limb (Leavitt and Beasley, 1964; Timberlake 1964; Webster, 1964).

The electromyographic method of Burke, Gillies,,$\stackrel{0}{\supset}$ and Lance (1970) has been adapted for this trial and,, together with a clinical assessment, has been used too compare the effect of placebo and $34,647-\mathrm{Ba}$ on $\frac{\mathrm{C}}{9}$ human spasticity. An uncontrolled comparison with diazepam has also been included.

\section{PATIENTS AND METHODS}

Six patients were studied in this preliminary trial, and they remained in hospital for its duration. All were quadriparetic or quadriplegic from injury to the lower cervical spinal cord. The lesion was clinically complete in two patients. Five had suffered their injury within the preceding 12 months, and the sixth patient four years previously. There were two females and four males, aged from 17 to 41 years. All had established spasticity and had been treated for one to three months with diazepam in a dosage range from 15 to $30 \mathrm{mg}$ daily.

The patients were assessed clinically and electromyographically when on diazepam which was then suspended 24 hours before the start of the double blind section of the trial. The duration of the double blind trial was 28 days, so that each patient received $34,647-\mathrm{Ba}$ or placebo for 14 days followed by the alternative for a further 14 days.

The initial dose of 34,647-Ba was $15 \mathrm{mg}$ daily in three divided doses. This was increased by $15 \mathrm{mg}$ every three days to a maximum of $60 \mathrm{mg}$ daily, and after four days at this level the electromyographic assessment was repeated. Placebo tablets were administered in an identical manner. Random allocation was such that half the 
patients were on the active drug and half on placebo during the first 14 days.

The patients were assessed clinically each day by two of the authors and a physiotherapist. Spasticity was assessed in five grades: normal muscle tone (0), slight (1), moderate (2), severe (3), limb rigid (4). Muscle power was recorded using the Medical Research Council scale. The duration of ankle clonus was measured in seconds, longer than 30 seconds being regarded as maximal. Tendon reflexes were recorded as reduced (1), normal (2), increased (3), and markedly increased (4). The number of spasms were recorded daily by the patients.

The electromyographic assessment was performed when on diazepam, and after both 14 day periods of active drug or placebo. The EMG of the quadriceps muscle, produced by passive flexion of the knee joint, was recorded by surface electrodes 15 to $20 \mathrm{~cm}$ apart, and integrated (time constant $0.2 \mathrm{sec}$ ). The same electrode position was used for the three assessments of each patient. The knee joint angle was measured by a goniometer, and its output was differentiated (time constant $5 \mathrm{msec}$ ) to produce a voltage proportional to angular velocity. The direct EMG, integrated EMG, joint angle and angular velocity were recorded simultaneously on a four channel Offner dynograph. The direct EMG was also monitored on an oscilloscope to detect movement artefact. For movements starting from full extension, angular velocity was plotted against integrated EMG, and linear regression analysis was performed for those movements which produced EMG. The EMG: velocity relationship was then defined in terms of slope of the regression line, and the intercept of the regression line on the velocity axis (minimal velocity for production of a stretch reflex). The EMG produced at $200^{\circ} / \mathrm{sec}$ while the patient was on each medication was used as a point of comparison because it is a reasonable upper limit to the rate of physiological movement.

Side-effects were elicited by direct questioning. Blood pressure and pulse rate were recorded twice daily, urinalysis was performed daily and microurine weekly. Full blood count, ESR, blood urea, serum electrolytes, liver function tests, and electroencephalogram (EEG) were performed before the start of the trial and then every two weeks.

\section{RESULTS}

\section{CLINICAL ASSESSMENT}

DOUBLE BLIND TRIAL Muscle tone was diminished in five out of six patients on 34,647-Ba compared with placebo (Fig. 1). Muscle spasms were less frequent in three patients (Fig. 2), and clonus was less persistent in two of the four patients in whom clonus was sustained. No consistent change was found in tendon reflexes. There was an appaient increase in muscle power in three patients and no regression in the other three. In the sixth patient who failed to improve in any of the clinical parameters,

the dose of 34,647-Ba was subsequently increased to $75 \mathrm{mg}$ daily, producing marked improvement in tone and number of spasms.

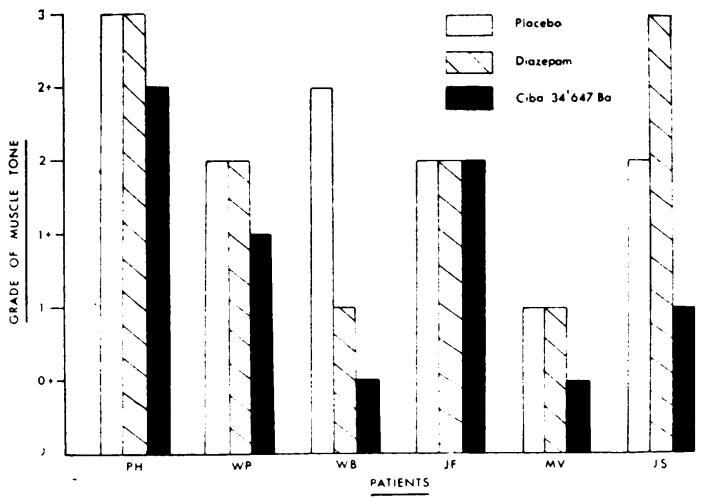

FIG. 1. Clinicat assessment of muscle tone.

COMPARISON WITH DIAZEPAM Control of spasticity and muscle spasms was better with $34,647-\mathrm{Ba}$ in five patients. Fewer spasms were recorded in three patients when on placebo than on diazepam. In one of these, muscle tone was also less marked when on placebo. Two of the three patients had complete cord lesions.

\section{ELECTROMYOGRAPHIC ASSESSMENT}

DOUBLE BLIND TRIAL In all six patients, for any given velocity of stretch, the stretch reflex was less during treatment with $34,647-\mathrm{Ba}, 60 \mathrm{mg} /$ day. At a velocity of $200^{\circ} / \mathrm{sec}$, the stretch reflex was abolished

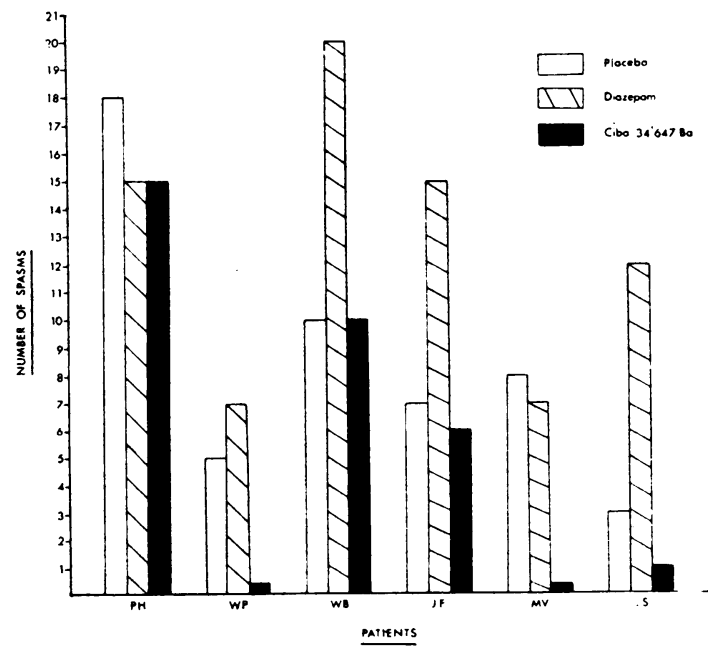

FIG. 2. Number of spasms per day. 
or diminished to a mean of $37.5 \%$ (range $0-67 \%$ ) of the value obtained when the patient was on placebo. This reduction in stretch reflex was responsible for an increase in the minimal velocity required to produce a stretch reflex, and a decrease in the slope of the EMG: velocity relationship (Fig. 3).

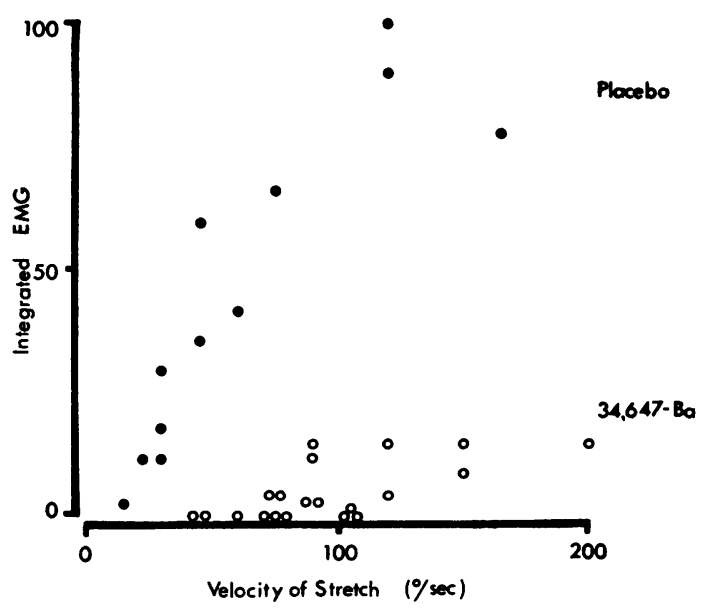

FIG. 3. The therapeutic effect of 34,647-Ba; the increase in minimal velocity for production of a stretch reflex and the decrease in slope together reflect the decreased level of spasticity produced by 34,647-Ba as compared with placebo. At any given velocity less EMG was produced when the patient was on $34,647-B a$.

In three patients this minimal velocity was greater on $34,647-\mathrm{Ba}$ than on placebo; in one of these patients, no stretch reflex was recorded when on 34,647-Ba.

In the remaining three patients, when on placebo, the slowest movement produced a stretch reflex. In two of these three patients, when on $34,647-\mathrm{Ba}$, minimal velocities of $23^{\circ} / \mathrm{sec}$ and $104^{\circ} / \mathrm{sec}$ were required to produce EMG activity (Fig. 4). In the third patient when on $34,647-\mathrm{Ba}$, slow stretching movements still produced EMG but the slope of the EMG: velocity relationship had decreased (Fig. 5). In two other patients a similar change in slope was noted in addition to the increase in minimal velocity.

COMPARISON WITH DIAZEPAM In four patients, 34,647-Ba appeared more effective than diazepam. In one patient there was no significant difference, and in the sixth, diazepam was slightly more effective (minimal velocity $41^{\circ} / \mathrm{sec}$ as against $23^{\circ} / \mathrm{sec}$ ). In this patient, who had shown no clinical improvement on $34,647-\mathrm{Ba}$, the dose was increased to $75 \mathrm{mg} / \mathrm{day}$, resulting in a marked reduction in stretch reflex with an increase in minimal velocity to $145^{\circ} / \mathrm{sec}$ (Fig. 4).

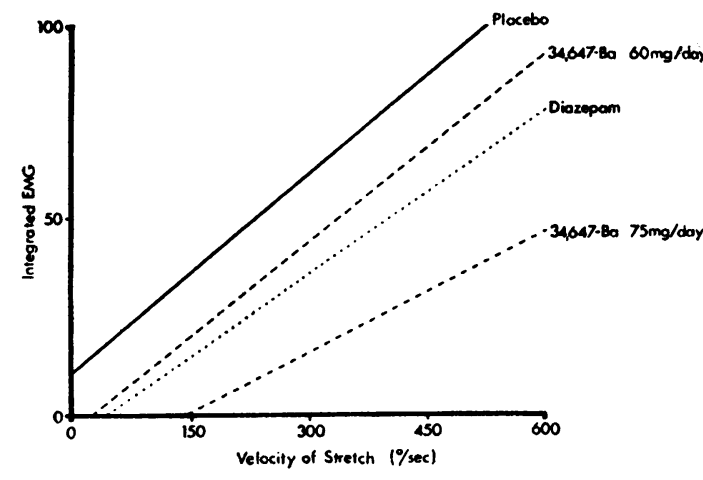

FIG. 4. The effect of a higher dosage of 34,647-Ba in a patient with intense spasticity: each line represents the $\vec{O}$ calculated line of best fit of multiple recordings. When on placebo even the slowest movements produce EMG. The $\bar{\omega}$ minimal velocity was increased to $23^{\circ} / \mathrm{sec}$ when on $34,647-$

$\mathrm{Ba} 60 \mathrm{mg} /$ day, and $41^{\circ} / \mathrm{sec}$ when on diazepam. A dose of 34,647-Ba $75 \mathrm{mg} /$ day increased the minimal velocity to $145^{\circ} / \mathrm{sec}$.

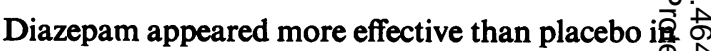
three patients, reducing the EMG obtained at $200 \%$ sec to a mean of $40 \%$. In two patients no significan difference was demonstrable, while in the sixt patient a greater stretch reflex was produced when on diazepam. In this patient the minimal velocity was $187^{\circ} / \mathrm{sec}$ when on placebo and $123^{\circ} / \mathrm{sec}$ when on. diazepam. There was no change in slope of the EMG velocity relationship.

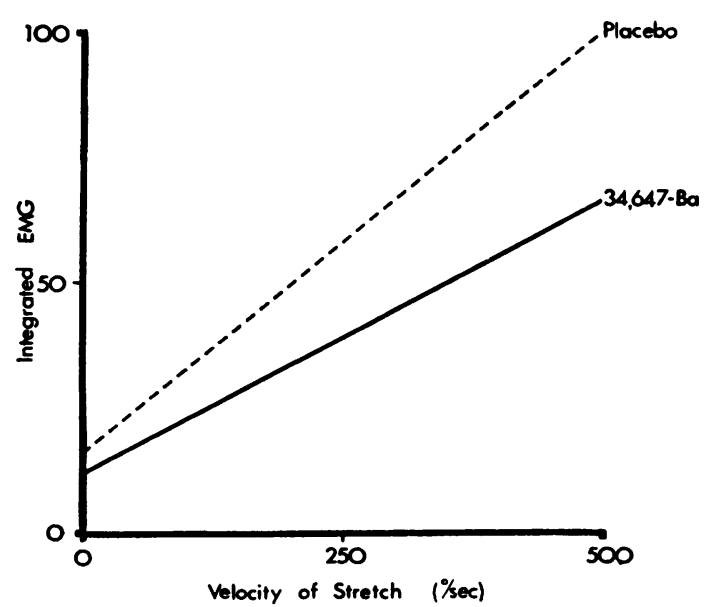

FIG. 5. The effect of 34,647-Ba in a patient with intense spasticity: when on both placebo and 34,647-Ba, spasticity was so intense that a stretch reflex was produced at all velocities, but the magnitude of the stretch reflex was less when on $34,647-B a$. 
3. SIDE-EFFECTS No serious side-effects were noted during the trial and no alteration of drug regime was necessary.

The most consistent side-effects, occurring in five patients on 34,647-Ba and two patients on placebo, were transient attacks of nausea with sweating or vertigo. These attacks lasted 10 to 20 minutes and responded to bed rest. Diarrhoea with incontinence occurred in two patients on $34,647-\mathrm{Ba}$ and two on placebo. Two patients noted easy fatiguability and muscular weakness for one day but this did not recur despite continuation of treatment. One patient became depressed transiently while on $34,647-\mathrm{Ba}$.

Previously documented side-effects of excessive salivation, thirst, sedation, confusional states, euphoria, and hypotension were not observed. No renal, haematological, or hepatic abnormalities were detected. There was no change in blood pressure and no abnormality in urine microscopy.

Two patients were found to have abnormal EEGs when on placebo. In one, scattered theta waves were seen bilaterally on overbreathing with an exaggerated photo-myoclonic response on photic stimulation, indirectly indicating a lowered convulsive threshold. Electroencephalograms taken when on both diazepam and 34,647-Ba were within normal limits. In the other patient when on placebo, focal spike discharges were found with paroxysms of atypical spike and wave appearing bilaterally on overbreathing. When on 34,647-Ba, the EEG revealed paroxysmal abnormalities, similar in nature but much less in amount. No such epileptic activity was found in the record taken when on diazepam.

\section{DISCUSSION}

In spasticity, the stretch reflex of the quadriceps muscle depends on two variables: the velocity of stretch and the starting length of the muscle. The amplitude of the stretch reflex is proportional to the velocity of stretch, and inversely proportional to the length of the muscle being stretched (Burke et al., 1970). To control these variables during electromyographic assessment, the starting length of the quadriceps muscle was kept constant (full extension) and a range of velocities was used. At any given velocity, a smaller stretch reflex indicates decreased spasticity. Reduction in spasticity will be shown by a decrease in slope of the EMG : velocity relationship - (velocity sensitivity of the stretch reflex) and an increase in the minimal velocity required to produce the stretch reflex (threshold velocity).

On electromyographic testing, all six patients improved when taking 34,647-Ba $60 \mathrm{mg} /$ day. On clinical testing, only five patients appeared to be improved on this dosage, but the sixth patient responded clinically to $75 \mathrm{mg} /$ day, and further improvement was demonstrated electromyographically (Fig. 4). In another patient (Fig. 5) the reduction in spasticity produced by $34,647-\mathrm{Ba}$ was slight as judged by both clinical and electromyographic criteria, and this patient appeared equally resistant to diazepam. Although both drugs reduced the amount of reflex to $67 \%$, the threshold of the stretch reflex did not alter thus explaining the modest degree of clinical improvement.

The electromyographic technique provided a more sensitive assessment than clinical criteria, especially with mild or severe degrees of spasticity. For spasticity of moderate severity, clinical assessment appeared adequate.

The various clinical manifestations of the spastic state were not equally improved. Muscle tone improved in all patients, muscle spasms and clonus were alleviated in some patients, while tendon reflexes showed no consistent change. This contrasts with the findings reported in the decerebrate animal, in which $34,647-\mathrm{Ba}$ suppressed flexor reflexes more than decerebrate rigidity.

The dosage of diazepam used in this trial (15 to 30 $\mathrm{mg} /$ day) exceeded the dosage of 4 to $8 \mathrm{mg}$ daily found to be therapeutically effective by Levine et al. (1969), and had been given for a comparable period of time. In spite of this, diazepam was more effective than placebo in only three patients. However, in neither trial was the administration of diazepam randomized, and a non-specific response to new therapy cannot be excluded.

34,647-Ba was as effective in the two patients with complete cord lesions as in the other four patients. It therefore appears to have a site of action in the spinal cord, as has been suggested for diazepam (Cook and Nathan, 1967).

In this trial, 34,647-Ba was well tolerated, and no significant side-effects were encountered. The absence of the previously reported side-effects may have been due to the gradual increase in dosage, and a maximum dose of $60 \mathrm{mg} / \mathrm{day}$. In one patient a higher dosage was well tolerated.

The authors are grateful to Associate Professor J. W. Lance and Dr. G. G. Burniston for their guidance, and to Miss A. M. Mackie, chief pharmacist of The Prince Henry Hospital, who kindly arranged the random allocation of CIBA 34,647-Ba and placebo for the trial. We also wish to thank Miss S. Biggins, physiotherapist, and Sister E. Lyons, sister-in-charge, Spinal Injury Unit, The Prince Henry Hospital. CIBA Co. Pty. Ltd. kindly provided supplies of $34,647-\mathrm{Ba}$ for clinical trial, and illustrations were prepared by the Department of Medical Illustration, University of New South Wales. This work was supported in part by grants from the National Health and Medical Research Council and the Adolph Basser Trust. 


\section{REFERENCES}

Bergamini, L., Riccio, A., and Bergamasco, B. (1966). Un farmaco ad azione antispastica della muscolatura striata. Sperimentazione clinica di un derivato del Gaba. Minerva med., 57, 2723-2729.

Birkmayer, W., Danielczyk, W., and Weiler, G. (1967). Zur Objektivierbarkeit des myotonolytischen Effektes eines Aminobuttersäurederivates (CIBA 34,647-Ba) Wien. med. Wschr., 117, 7-9.

Burke, D., Gillies, J. D., and Lance, J. W. (1970). The quadriceps stretch reflex in human spasticity. J. Neurol. Neurosurg. Psychiat., 33, 216-223.

Castaneda, C. (1967). Investigacion de CIBA 34,647-Ba en los sindromes espasticos neurologicos. Sem. méd. Méx., 54, 13-16.

Cook, J. B., and Nathan, P. W. (1967). On the site of action of diazepam in spasticity in man. J. neurol. Sci., 5, 33-37.

Jerusalem, F. (1968). Doppeltblindstudie über den antispastischen Effekt von $\beta$-(4-Chlorophenyl)- $\gamma$-amino- buttersäure (CIBA) bei Multipler Sclerose. Nervenarzt, 39, 515-517.

Leavitt, L. A., and Beasley, W. C. (1964). Clinical application of quantitative methods in the study of spasticity. Clin. Pharmacol. Ther., 5, 918-941.

Levine, I. M., Jossmann, P. B., De Angelis, V., and Kane, M. (1964). Quantification of the electromyogram in neurospastic disorders. Clin. Pharmacol. Ther., 5, 893-899.

Levine, I. M., Jossmann, P. B., Friend, D. G., DeAngelis, V., and Kane, M. (1969). Diazepam in the treatment of spasticity. A preliminary quantitative evaluation. $J$. chron. Dis., 22, 57-62.

Morales, L. R. (1967). Efectos clinicos y terapeuticos del CIBA $34,647-\mathrm{Ba}$ en los sindromes espasticos. Mex. Med., 2, 187-192.

Timberlake, W. H. (1964). Evaluation of hypertonia with the use of a gravity-driven ergograph. Clin. Pharmacol. Ther., 5, 879-882.

Webster, D. D. (1964). The dynamic quantitation of spasticity with automated integrals of passive motion resistance. Clin. Pharmacol. Ther., 5, 900-908. 